EDUCAÇÃO

V.10 • N.2 • Número Temático - 2020

ISSN Digital: 2316-3828

ISSN Impresso: 2316-333X

DOI: 10.17564/2316-3828.2020v10n2p66-79

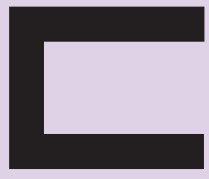

开 $N$ 开 立同(

CIENTÍFICAS

\title{
CIDADES DIGITAIS E SOCIEDADE EM REDE: INTERSECCÕES E DESAFIOS DE UMA CONSTRUÇÃO SOCIOTÉCNICA
}

DIGITAL CITIES AND NETWORK SOCIETY: INTERSECTIONS AND CHALLENGES OF A SOCIOTECHNICAL CONSTRUCTION

\section{CIUDADES DIGITALES Y SOCIEDADDE RED: INTERSECCIONES Y DESAFÍOS DE UNA CONSTRULCIÓN SOCIOTÉCNICA}

Diogo de Calasans Melo Andrade ${ }^{1}$ Letícia Feliciana dos Santos $\mathrm{Cruz}^{2}$

Fagner Farias Rodrigues ${ }^{3}$

\section{RESUMO}

No processo de globalização e das novas interações ciberespaciais observa-se o impulso na transição de cidades tradicionais em cidades digitais, como também o seu encaminhamento para cidades inteligentes. Nesse sentir, o presente estudo cumpre enfatizar a evolução da sociedade informacional e o contexto das cidades conectadas enquanto projetoras das relações e operações interligadas em redes (TIC, IOT e outros). Entretanto, a pesquisa de cunho qualitativa e técnica exploratória expõe que, embora o direito à internet tenha sido elencado no rol dos direitos humanos desde 2011, há na atual sociedade brasileira muitos indivíduos excluídos desse processo de modernização, sendo, portanto, impasse notório para a construção da cidadania digital plena. Uma vez que, o efetivo uso da internet e a construção de redes sociotécnicas viabilizam acesso aos meios de comunicação a todos os cidadãos, desempenhando, portanto, papel importante como ferramenta de democratização do conhecimento.

\section{PALAVRAS-CHAVE}

Cidades Digitais. Novas Tecnologias. Políticas Inclusivas. Redes Sociotécnicas. Sociedade em Rede. 


\section{ABSTRACT}

In the process of globalization and new cyberspace interactions, there is an impulse in the transition from traditional cities to digital cities, as well as their move towards smart cities. In this sense, the present study emphasizes the evolution of the information society and the context of connected cities as projectors of relationships and operations interconnected in networks (ICTs, IOT and others). However, the qualitative and exploratory technical research exposes that, although the right to the internet has been listed in the list of human rights, since 2011, there are in the current Brazilian society many individuals excluded from this modernization process, being, therefore, a notorious impasse for the construction of full digital citizenship. Since, the effective use of the internet and the construction of socio-technical networks enable access to means of communication for all citizens, thus playing an important role as a tool for democratization of knowledge.

\section{KEYWORDS}

Digital Cities. New technologies. Inclusive Policies. Sociotechnical Networks. Network Society.

\section{RESUMEN}

En el proceso de globalización y las nuevas interacciones en el ciberespacio, existe un impulso en la transición de las ciudades tradicionales a las ciudades digitales, así como su movimiento hacia las ciudades inteligentes. En este sentido, el presente estudio enfatiza la evolución de la sociedad de la información y el contexto de las ciudades conectadas como proyectores de relaciones y operaciones interconectadas en redes (TIC, IOT y otros). Sin embargo, la investigación técnica cualitativa y exploratoria expone que, aunque el derecho a Internet ha sido incluido en la lista de derechos humanos, desde 2011, en la sociedad brasileña actual, muchas personas están excluidas de este proceso de modernización, siendo, por lo tanto, un impase notorio para La construcción de la ciudadanía digital completa. Desde entonces, el uso efectivo de Internet y la construcción de redes sociotécnicas permiten el acceso a los medios de comunicación para todos los ciudadanos, desempeñando así un papel importante como herramienta para la democratización del conocimiento.

\section{PALABRAS CLAVE}

Ciudades digitales. Nuevas tecnologías. Políticas inclusivas. Redes sociotécnicas. Sociedad de red. 


\section{INTRODUÇ̧̃̃o}

O presente estudo busca abordar perspectivas e desafios existentes dentro da atual sociedade em rede 4 , bem como a tarefa de reconfiguração das cidades tradicionais em cidades conectadas, precisamente conhecidas como cidades digitais, as quais fomentam espaços de ligação entre o meio físico e o ambiente cibernético. Portanto, compreende-se que a cidade digital representa uma imersão no espaço e cultura ciber, de modo que apresenta mudanças significativas no cotidiano de seus habitantes a partir das tecnologias inovadoras.

Logo, há de se reconhecer que a conceituação de cidades digitais se encontra diretamente ligada à ideia de inclusão do binômio "cidadão-espaço" ao meio ambiente. Nesse caminhar, ressalta-se a tramitação do programa do governo federal intitulado "Cidades Digitais", sendo instituído por meio da Portaria n 376, de 19 de agosto de 2011, publicada no Diário Oficial da União em 22 de agosto de 2011, a qual propõe difundir a democratização do acesso à informação.

O estudo avança e, a partir de técnica exploratória e pesquisa qualitativa, propõe tecer considerações acerca da interconexão entre cidades digitais e sociedade em redes sob a perspectiva das novas tecnologias como ferramenta primordial para o desenvolvimento humano e construto social na atualidade. Dito isto, importa destacar que a coletiva de redes sociotécnicas proposta por meio dos portais de infoinclusão, implementados a partir dos Cidades Digitais, pauta-se nas benesses de interatividade a serviços comunicacionais diversos, objetivando uma maior difusão e acesso ao meio digital.

Por outro lado, observa-se que apesar do acesso à internet ser reconhecido como direito humano e por isso direito de todos, grande parte da população ainda não alcançou este avanço virtual, embora encaminhe-se para uma sociedade em rede (CASTELLS, 2006). Dito isto, imperioso se faz rememorar que durante toda historicidade da humanidade grande parcela dos indivíduos tendem a ficar à margem da sociedade, direcionados, assim, a não participar ativamente de importantes processos sociais. E, embora a atual sociedade de informações adote um conceito mais inclusivo e de transparência aos cidadãos, o padrão de gentrificação se repete, uma vez que os indivíduos com baixa instrução e qualidade de vida vêm tornando-se vítimas de uma exclusão dita sociodigital.

Como consequência disso, um novo grupo de excluídos se formou na sociedade contemporânea, tendo em vista não possuírem habilidades desenvolvidas por meio da (re)educação digital para lidar com a tecnologia. Assim, importante se faz a pesquisa ao ponderar os entraves ora encontrados ao tratar da construção de redes sociotécnicas nas cidades digitais, seus direcionamentos, alcances e encaminhar para uma cidadania digital efetiva. Logo, para erradicar essa exclusão digital torna-se urgente investir em políticas públicas inclusivas, de modo que sejam levantadas alternativas que cumpram garantir a inserção educacional e acessibilidade às novas tecnologias para todos os cidadãos.

4 As novas tecnologias de comunicação e informação têm transformado vários segmentos da sociedade contemporânea, fazendo com que diversos analistas tenham sugerido classificar a época como "[...] sociedade da informação ou informacional, cibercultura, sociedade em rede etc." (LEMOS, 2004, p. 136). 


\section{SOCIEDADE [INJFORMACIONAL: O QUE MUDA COM A IMPLEMENTAÇ̃̃O DAS CIDADES DIGTAIS?}

As cidades vêm passando por inúmeras transformações desde o período pós-industrial, ora impulsionadas pelas inovações tecnológicas. Dito isto, frisa-se que as novas tecnologias informacionais e de comunicação são aprimoradas constantemente. De modo que, o período atual e sua fluidez corresponde ao que o sociólogo Zygmunt Bauman (2001) denomina como modernidade líquida. Nas últimas duas décadas pôde-se observar uma grande expansão informacional devido ao súbito desenvolvimento e difusão tecnológica. Nunca se criou tanto no campo da tecnologia quanto tem sido criado nos tempos atuais; smartphones, tablets, televisores e relógios com acesso à internet fazem com que as pessoas estejam cada vez mais conectadas ante ao que o sociólogo espanhol Manuel Castells chama de Sociedade em Rede. Nesse sentido Castells (2002, p. 67) discorre:

[...] estamos vivendo um desses raros intervalos na história. Um intervalo cuja característica é a transformação de nossa 'cultura material' pelos mecanismos de um novo paradigma tecnológico que se organiza em torno da tecnologia da informação.

No século vigente, os avanços tecnológicos não só evoluíram junto com a espécie humana como possibilitam que os humanos continuem a evoluir e de forma ainda mais acelerada. É possível realizar diversas operações bancárias por meio do celular, consultas médicas podem ser realizadas por videoconferência, as mídias sociais tornaram-se fontes importantes de informação, lazer, ferramentas educacionais e até mesmo o aprimoramento genético humano já se tornou realidade.

Destarte, no tocante ao cenário das cidades conectadas e as constantes interações em rede, há de se apontar que a implementação das cidades digitais cumpre revolucionar o cotidiano da atual sociedade a partir de mecanismos tecnológicos que facilitem os acessos entre o meio físico e as esferas virtuais. Diante desse contexto, os autores Ismael Mattos A. Ávila e Giovanni Moura de Holanda (2006, p. 56) afirmam que:

[...] o cidadão pode exercer mais plenamente sua cidadania, fazendo uso de serviços públicos, como governo eletrônico, de capacitação (educação a distância), de saúde e de acesso a redes de dados e de informação, como a Internet. Isso pode, em consequência, ampliar sua capacidade de comunicação, habilitando-o a usufruir de conteúdos locais e globais. Com isso, há um aumento da base de conhecimento individual e coletiva, o que permite reforçar identidades culturais. Nesse sentido, é fundamental que os indivíduos reúnam não apenas condições para acessar e decodificar os conteúdos ofertados por esses serviços, como tenham condições de produzir conteúdos voltados às suas necessidades e a seu contexto sociocultural.

Sob essa perspectiva, observa-se que o avançar da implementação de cidades digitais contribui para com o desenvolvimento do indivíduo em sociedade, ora enquanto integrante de comunidades virtuais, bem como amplia o seu acesso aos serviços públicos por meio de governos eletrônicos e redes sociotécnicas, redes essas mediadas pelas tecnologias inovadoras. 


\section{AS CIDADES DIGITAIS E SEU PAPEL INCLUSIVO: QUEBRA DA CONCEPÇÃO UTÓPICA}

Uma cidade digital deve conceder aos seus usuários a oportunidade de desenvolvimento frente as redes de informações, construindo ambientes no qual realiza-se a transferência de conhecimentos e experiências profissionais, mas não somente isso, as cidades digitais visam descomplexificar diversas atividades econômicas e sociais da vida humana, como transporte, educação, lazer, segurança e saúde. Nesse sentido, expõe Evandro Prestes Guerreiro (2006, p. 221-222):

[...] defino a cidade digital como o ambiente ou a plataforma de rede digital criada no território que interliga sistemas tecnológicos avançados para conectar serviços públicos, bens, marcas, escolas, organizações do terceiro setor, empresas, micro e macro comunidades de pessoas, disponibilizando informações em diversas ordens e padrões com o propósito de desenvolver as potencialidades da sociedade de informações e transformar o cidadão em ator e protagonista de uma outra realidade: a virtual.

Ademais, embora essa apresente um conceito promissor, ainda permanece o questionamento sobre como uma cidade digital conseguiria agregar positivamente no cotidiano da sociedade. A resposta para essa indagação se dá por meio de duas das principais funções de uma cidade digital, quais sejam a inovação colaborativa e a promoção de comunidades e região.

A primeira função significa dizer que em uma cidade digital há o desenvolvimento de sistemas que fornecem aos cidadãos a construção de grupos virtuais munidos de aparatos que auxiliam no aprimoramento do mercado de forma colaborativa, portanto, como possui um meio colaborativo entre todos os agentes, a consequência é o aperfeiçoamento da inovação humana. Já a segunda função está relacionada à perspectiva de criação de espaços que fomentam a promoção de espaços físicos por meio de ferramentas digitais, nas palavras de Bredas, Mendes e Panhan (2016, p. 36-37):

Os espaços digitais podem facilitar, aprimorar e reduzir os custos de todos os tipos de transações como logística, publicidade, informações políticas, regulamentos, normas técnicas, procura de parceiros, compradores, vendedores e serviços.

Assim, a construção de cidades interligadas amplia os espaços para interação em rede, seja numa perspectiva de maior inclusão socioespacial, como também em se tratando de um maior aprimoramento e uso das novas tecnologias no cotidiano, as quais buscam aproximar serviços inteligentes à sociedade em rede.

Por conseguinte, ao falar em cidade digital é comum pensar em algo distante e inatingível, já que normalmente vem ao imaginário imagens de cidades futuristas apresentadas em obras cinematográficas e séries de TV, no entanto, cidades digitais já são realidade, mas de forma ponderada, não como as extravagantes cidades exibidas em obras de ficção. Essas cidades, que em sua suma maioria são turísticas, visam atender os anseios de seus povos, além de ofertar informações turísticas e comerciais condizentes com a cidade física. Na obra A Virada Digital: Smart Cities e Smart Grids em uma 
perspectiva multidisciplinar, organizada por Milla Benício, há o relato de como o ambiente digital e o ambiente material estão sendo interligados para proporcionar benefícios na vida das pessoas.

[...] uma pequena cidade localizada no norte da Espanha chamada Santander. Com aproximadamente 12 mil sensores espalhados pela cidade, todos os moradores e turistas de Santander têm acesso a informações como a qualidade do ar as condições do trânsito - gargalos, lentidão no tráfego, obras e acidentes (são mapeados em tempo real) - e vagas disponíveis de estacionamento em vias públicas (evitando que veículos transitem além de suas necessidades). Ademais, conectados aos semáforos, existe um sistema de detecção sonora em regiões próximas aos hospitais, a fim de captar o som sirene de ambulâncias facilitando sua chegada - ao abrir, automaticamente, os sinais de trânsito no de correr do caminho. Além disso, câmeras nas principais vias da cidade auxiliam na avaliação da capacidade dos veículos e na necessidade de aumento ou redução de frota. No que tange ao transporte público, todos os ônibus e táxis (e também carros de polícia) transmitem a sua posição e velocidade. Os pontos de ônibus informam detalhes sobre as linhas e os horários de chegada e partida dos ônibus, além de terem sistemas multimodais de transporte público (ônibus, metro, VLT, bicicletas e trens) que, quando combinados, oferecem à população uma integração completa e abrangente dos serviços de mobilidade urbana. (BENICIO, 2019, p. 152).

No tocante aos impasses enfrentados quanto da aplicabilidade e implementação das cidades digitais, há de se ressaltar os entraves jurídicos levantados durante a presente pesquisa, uma vez que se por um lado as cidades digitais são vistas como um novo reordenamento espacial, qual seja de maior interligação entre o campo físico e o virtual, por outro lado as interações e circulações de dados, sem efetivo sistema de proteção desses, despertam riscos à violação do direito à privacidade, direito garantido pela Constituição Federal de 1988 no Art. $5^{\circ}$, sendo colocado em questão tanto o direito à privacidade quanto o direto à segurança.

Todavia, é imprescindível compreender que o estado de vigilância que se desenvolve em um cenário de expansão tecnológica não ocorre somente por meio de ferramentas explícitas, como sistemas de câmeras de monitoramento, essa vigilância advém também por meio de atividades comuns no dia a dia das pessoas, como informar o número do Cadastro de Pessoas Físicas (CPF) ao realizar uma compra ou cadastrar diversos dados pessoais para poder realizar o cadastro em algum site. Dessa forma, David Lyon e Zygmunt Bauman (2014, p. 4) tratam a vigilância como algo em constante metamorfose:

A vigilância é um aspecto cada vez mais presente nas notícias diárias, o que reflete sua crescente importância em muitas esferas da vida. Mas, na verdade, a vigilância tem se expandido silenciosamente por muitas décadas e é uma característica básica do mundo moderno. À medida que esse mundo vem se transformando ao longo de sucessivas gerações, a vigilância assume características sempre em mutação. Hoje, as sociedades modernas parecem tão fluidas que faz sentido imaginar que elas estejam numa fase "líquida". Sempre em movimento, mas muitas vezes carecendo de certezas e de vínculos duráveis, os atuais cidadãos, trabalhadores, consumidores e viajantes também desco- 
brem que seus movimentos são monitorados, acompanhados e observados. A vigilância se insinua em estado líquido.

Sobretudo, torna-se inescusável analisar e ponderar qual alternativa tende a ser mais vantajosa para a comunidade em geral e para o particular, de modo que se faz necessário avaliar as medidas que maior zelem pela efetiva garantia à privacidade e que possam contribuir para uma melhoria em aspectos do cotidiano, como o aprimoramento da segurança por meio de sistemas de monitoramento e vigilância menos invasivo.

\title{
4 CIDADES DIGITAIS E CIDADES INTELIGENTES: REFLEXOS DE UMA TRAJETÓRIA
}

Neste trilhar, ressalta-se o processo de reordenação do espaço urbano e das novas espacialidades a partir de gerenciamentos informatizados, dito isto há de se destacar a produção de cidades digitais e seu encaminhamento para cidades inteligentes. De modo que a inteligência urbana se tornou inevitável, emergindo de um contexto socialmente integrado para espacialmente contingente. Ademais, realizando um balanço histórico primoroso, a autora Lúcia Santaella (2016, p. 25) aponta que:

\begin{abstract}
O tema das cidades inteligentes começou a surgir nos anos 2000 para se transformar hoje em uma constante. A razão para isso encontra-se não apenas no crescimento desmesurado das megalópoles e no surgimento contínuo de novas metrópoles, mas encontra-se também na expansão crescente da internet nos espaços domésticos, públicos, corporativos governamentais e sai correspondente incorporação na necessária infraestrutura material das cidades.
\end{abstract}

Assim, sob o cenário das cidades globalizadas e cultura ciber fundamental se faz esclarecer a divergente conceituação entre cidade digital e cidade inteligente, uma vez que as formas de interações são distintas, embora na maioria das vezes sejam usadas como sinônimas. Assim sendo, de forma clara e simplória, expõe Bredas, Mendes e Panhan (2016, p. 55):

[...] a Cidade Inteligente é a Cidade Digital que desenvolve a capacidade de interagir com a sociedade de forma automática, atendendo os cidadãos com serviços inteligentes que auxiliem em seu dia a dia, melhorando a qualidade de vida geral da sociedade.

Portanto, tem-se observado nas últimas décadas que a capacidade de inovação nas cidades tem sido uma constante, haja vista o poder de influência das novas tecnologias e de ambientes criativos. Logo, sobre o direcionamento de cidades inteligentes no atual cenário brasileiro, salientam os autores Carlos Leite e Juliana di Cesare Marques Awad (2012, p. 133), que:

Cidades mais inteligentes no Brasil são também a incorporação dos inovadores e promissores instrumentos de tecnologia da informação e comunicação na promoção de melho- 
res e mais otimizados territórios informais, tão extensos e populosos nas nossas cidades, e cujo desafio de inserção à rede urbana "formal" - e não a sua exclusão - é dotá-lo de adequadas infraestruturas.

Vale dizer que, representada pelo símbolo da modernidade, as cidades intituladas inteligentes são sistemas que procuram incrementar a qualidade de vida e o conforto do ser humano por sistemas interativos com alto nível de tecnologia e flexibilidade que atendam às necessidades dos cidadãos hodiernamente. De modo tal, sobre o desenvolvimento desses espaços, explica Carlos Leite e Juliana Awad (2012, p. 133), que:

Em uma perspectiva de um planeta com população cada vez mais urbana, com cidades cada vez maiores, dando origem a megacidades - cidades com populações acima de 10 milhões de habitantes - e megarregiões - conurbação de diferentes cidades em uma região muito mais ampla - é preciso desenvolver modelos de sustentabilidade urbana capazes de alinhar o desenvolvimento desses espaços com o respeito aos princípios da sustentabilidade. As cidades são elementos-chave para o desenvolvimento sustentável global.

Assim, frente ao processo de globalização e acentuado cenário tecnológico, a cidade acende para além do urbano, numa imersão das redes telemáticas, de modo que fazem parte da vida cotidiana e constituem-se como infraestrutura básica e hegemônica.

\section{A INTERNET COMO FERRAMENTA DE DEMOCRATIZAÇÃO DA INFORMAÇÃO E MODIFICAÇÃO DO COTIDIANO}

Apesar da ininterrupta transformação tecnológica acarretar a possibilidade do desenvolvimento de variados problemas sociais, vê-se que a evolução dos meios tecnológicos, ao menos em tese, viabiliza um maior acesso aos meios comunicacionais. Cumpre rememorar que, a partir dos anos 2000 a produção de conteúdo destinados à Internet passou por um aumento considerável, o desenvolvimento de plataformas como Facebook, YouTube e Netflix possibilitou uma maior acessibilidade a conteúdos que, até então, eram distribuídos quase que exclusivamente por meio televisivo e de modo hirto.

Por meio desse avanço tornou-se viável que a população mais carente pudesse ter acesso à videoaulas, documentários, filmes, músicas e conteúdos jornalísticos por um preço mais acessível, ou até mesmo gratuito. Acerca do andamento da inovação tecnológica na sociedade atual e suas influências, destacam Giovanni Moura de Holanda e Ismael Mattos A. Ávila (2006, p. 1) que:

Telecomunicações, computadores e software estão convergindo numa infraestrutura que tem, não apenas mudado o paradigma de comunicação, como construído uma plataforma para o desenvolvimento econômico e um meio para ampliar as interações sociais. Nos países desenvolvidos, a inovação tecnológica em termos de redes de comunicação, nota- 
damente o acesso sem fio e os modems para o acesso telefônico, tem impulsionado o desenvolvimento de suas novas Tecnologias da Informação e Comunicação (TICs), de novos formatos de conteúdo e de variados modelos de negócio. Tal tendência desponta como uma das forças motrizes do desenvolvimento econômico e social da sociedade moderna.

Pacotes de serviços de streaming de vídeo como Netflix e Amazon Prime Video podem ser considerados os principais exemplos de como a internet pode ser utilizada como uma ferramenta de democratização. A parcela carente da sociedade, que, de modo geral, habita regiões periféricas das cidades, raramente consegue ter acesso às salas de cinema, devido ao fato destas estarem posicionadas nos grandes centros urbanos e por possuírem altos valores de entrada.

Entretanto, os serviços de streaming de vídeo podem ser acessados a partir de qualquer computador, tablet, smart tv ou smartphone, até mesmo de maneira offline, desde que tenha sido efetuado o download do conteúdo previamente e possuem valores de assinatura comumente menores que os preços cobrados pelos ingressos dos principais filmes. Dessa forma, é possível obter acesso aos variados serviços com uma vasta quantidade de conteúdo, independentemente da localidade do assinante.

Pode-se mencionar que a era atual e a modificação do cotidiano estão marcadas também pela Internet das Coisas (IoT), conceito referente à interconexão entre objetos do cotidiano das pessoas e a rede mundial de computadores. Casas passaram a estar ligadas à assistentes virtuais que servem como ferramentas de entretenimento, mas que também auxiliam no gerenciamento da residência, carros estão ligados à sistemas de tráfego, indicando a melhor rota ao motorista e aparelhos de televisão conectam-se à internet, disponibilizando inúmeros conteúdos aos telespectadores, dentre outros exemplos.

Perante o exposto, verifica-se que a Internet das Coisas é o termo utilizado para indicar que o objeto está ligado à internet, fazendo parte de uma rede, na qual passa a interligar vários tipos de objetos e dispositivos inteligentes, ampliando, assim, as interações e os comandos virtuais, a fim de facilitar as mais diversas tarefas do dia a dia.

\section{DIREITO À INTERNET E REDES SOCIOTÉCNICAS: "ACESSO À TODOS" OU MAIS UM FATOR DE EXCLUSÃO?}

A mutação tecnológica incessante e desordenada acarreta o favorecimento do crescimento da desigualdade entre classes, apesar do direito à internet e seu acesso ter sido listado como um direito humano, direito inerente a todo e qualquer ser humano, ora elencado juridicamente pela Organização das Nações Unidas (ONU) no ano 2011. Tendo em vista que, os mais favorecidos financeiramente terão constante acesso às inovações fornecidas pelo mercado, enquanto aqueles com baixo poder aquisitivo permanecerão com um aparelho tecnológico defasado, ou em casos mais extremos, sequer possuirão condições de adquirir tais bens, mesmo que obsoletos. 
De acordo com a última pesquisa TIC Domicílios ${ }^{5}$, realizada em 2018, cerca de $33 \%$ dos domicílios brasileiros não possuem acesso à internet, sendo que em $27 \%$ desses casos os moradores não contratam o serviço de internet por considerarem de alto custo. Essa desigualdade acarreta, notadamente, na exclusão digital da população mais carente, sendo essa afastadas da possibilidade de construção de novas interações sociais, visto que, não só a internet, como a tecnologia digital, de modo geral, tornou-se uma ferramenta de grande valia na composição de relações sociais que ocorrem também fora do cenário digital, mas que tiveram seu estabelecimento a partir dessas. Desse modo Castells (p. 286-287) disserta:

[...] é a infra-estrutura tecnológica e o meio organizativo que permitem o desenvolvimento de uma série de novas formas de relação social que não têm sua origem na Internet, que são fruto de uma série de mudanças históricas, mas que não poderiam desenvolver-se sem a Internet. Esta sociedade em rede é a sociedade que eu analiso como uma sociedade cuja estrutura social foi construída em torno de redes de informação a partir da tecnologia de informação microeletrônica estruturada na Internet.

Essa exclusão digital, além de reduzir o acesso às ferramentas de lazer, direito garantido pelo artigo $6^{\circ}$ da atual Constituição Federal e cercear a probabilidade de novas interações sociais, também gera uma restrição ao acesso à informações diversas, já que os principais meios de comunicação atuais ocorrem por meio do ciberespaço.

Posto isto, ressalta-se que embora o acesso à internet seja também elegido à categoria de direito fundamental, vê-se uma realidade contrastante frente a democratização do seu uso. Uma vez que, enquanto a concentração de usuários de internet das classes média e alta atinge o total de $90 \%$, somente $42 \%$ da classe baixa usufruem desse acesso, segundo dados do Instituto de Pesquisa Econômica Aplicada (IPEA, 2019).

De mais a mais, segundo o filósofo e sociólogo Lévy Pierre (2005), o ciberespaço pode ser apontado como o meio de comunicação mais inclusivo, uma vez que permite a manifestação pública aos diversos grupos e indivíduos, da mesma maneira que propicia que todos tenham acesso a uma abundante quantidade de conhecimento. Sendo assim, aqueles que possuem o acesso a esse espaço “[...] poderão se revelar cidadão mais bem informados, politicamente mais ativos e socialmente mais conscientes que os cidadãos off line." (LÉVY, 2005, p. 376). Em apertada síntese, pensar a cidade e seus cidadãos nesse atual contexto exige ampliar os horizontes de ordenação e intervenções em políticas públicas atinentes a inclusão sociodigital e ao desenvolvimento humano, a priori.

\section{CONSIDERAÇÕES FINAIS}

A dinamização das relações comunicacionais a partir da difusão da internet corrobora para a imersão de uma cultura ciber, haja vista que se por um lado a sociedade encaminha-se para a in-

5 Disponível em: https://www.cetic.br/pesquisa/domicilios 
teração em redes, por outro as cidades tendem a se reinventarem, sendo inevitável a expansão da inteligência urbana e suas inovações.

Diante desse cenário, as cidades digitais e inteligentes interagem frente as novas espacialidades, bem como fomentam a construção de redes sociotécnicas e espaços de infoinclusão social. Dessa forma, compreende-se que pensar a cidade e seus cidadãos na contemporaneidade exige ampliar os horizontes de ordenação e planejamento, quer seja por meio de governos eletrônicos, perante as novas formas e interações da sociedade informacional.

De modo tal, o presente estudo alcançou defender a importância da implementação de cidades digitais para cidadãos digitalmente inseridos, ou seja, pautada numa sociedade participativa, atinente ao enfretamento das questões de segregação digital, assim como ampliar práticas voltadas a concretização dos direitos humanos como um meio de consagração do exercício da cidadania.

Dado o exposto, a internet tornou-se uma importante ferramenta para a democratização, porém, restou pontuado no decorrer do texto que ainda que existe na sociedade brasileira muitos indivíduos excluídos desse processo de modernização, sendo, portanto, impasses notórios para a construção da efetiva cidadania digital. Dessa forma, é possível não só estabelecer pontos vantajosos ao progresso tecnológico, como também é exequível e necessário salientar os pontos negativos.

Assim sendo, restou clarividente que o acesso à internet deve se fazer disponível e acessível a todos, haja vista o seu reconhecimento enquanto um direito humano, ora elencado pela Organização das Nações Unidas (ONU) em 2011, qual seja integralizado por meio de políticas públicas de cunho efetivo, uma vez que para erradicar esta exclusão digital é preciso investir em práticas de inclusão. De modo que sejam levantas alternativas que cumpram garantir a acessibilidade às novas tecnologias para todas os cidadãos.

Pela observação dos aspectos analisados, cabe salientar acerca da urgência no controle e proteção de dados compartilhados nas cidades conectadas, por meio de um governo eletrônico eficiente, que seja capaz de fomentar a segurança do acesso aos portais de infoinclusão e das redes sociotécnicas, fazendo jus a premissa do programa do governo federal intitulado “Cidades Digitais”, o qual contempla natureza de política pública, instituído por meio da Portaria n 376, de 19 de agosto de 2011, publicada no Diário Oficial da União em 22 de agosto de 2011, que visa uma maior interação entre o binômio cidade-cidadão, como também propõe difundir a democratização do acesso à informação.

Em síntese, mais do tecer considerações acerca da atual transição urbana-tecnológica e desse reordenamento do espaço urbano frente aos ambientes interligados, por meio das TIC, IoT e entre outros, tratar sobre os desafios e perspectivas das cidades digitais e da sociedade em rede, diz respeito sobre a urgência na inserção de práticas educacionais inclusivas e a concretização de uma cidadania digital plena.

\section{REFERÊNCIAS}

BAUMAN, Zygmunt. Modernidade líquida. Rio de Janeiro: Editora Zahar, 2001.

BAUMAN, Zygmunt; LYON, David. Vigilância líquida. Rio de Janeiro: Editora Zahar, 2014.

Interfaces Científicas - Aracaju • V.10 - N.2 - p. 66 - 79 - Número Temático - 2020 
BENICIO, Milla (org.). A virada digital: smart cities e smart grids em uma perspectiva multidisciplinar. Rio de Janeiro: Editora Interciência, 2019.

BREDA, Gean Davis.; MENDES, Leonardo de Souza. PANHAN, André Marcelo. Construindo cidades inteligentes. Curitiba: Editora Appris, 2016.

CASTELLS, Manuel. A sociedade em rede: a era da informação; economia, sociedade e cultura. São Paulo: Paz e Terra, 1999.

CASTELLS, Manuel. A era da informação: economia, sociedade e cultura. Volume I. A sociedade em rede. 6. ed. São Paulo: Paz e Terra, 2002.

CASTELLS, Manuel. Internet e sociedade em rede. In: MORAES, Dênis de (org.). Por uma outra comunicação: mídia, mundialização cultural e poder. 3. ed. Rio de Janeiro: Record, 2005.

GODOY, Arilda Schmidt. Pesquisa qualitativa: tipos fundamentais. Revista de Administração de Empresas, São Paulo, v. 35, n. 3, p, 20-29 maio/jun. 1995.

GUERREIRO, Evandro Prestes. Cidade digital: infoinclusão social e tecnologia em rede. São Paulo: Editora Senac São Paulo, 2006.

IPEA. Instituto de Pesquisa Econômica Aplicada. Disponível em: https://www.ipea.gov.br/portal/ index.php?option=com_content\&view=article\&id=34796. Acesso em: 30 out. 2019.

LEITE, Carlos; AWAD, Juliana di Cesare Marques. Cidades sustentáveis, cidades inteligentes: desenvolvimento sustentável num planeta urbano. Porto Alegre: Bookman, 2012.

LEMOS, André. Cidade-ciborgue: a cidade na cibercultura. Rev. Galáxia, São Paulo, n. 8, p. 129-148, out. 2004. Disponível em: https://revistas.pucsp.br/galaxia/article/view/1385. Acesso em: 15 out. 2019.

LÉVY, Pierre. Pela ciberdemocracia. In: MORAES, Dênis de (org.). Por uma outra comunicação: mídia, mundialização cultural e poder. 3. ed. Rio de Janeiro: Record, 2005. p. 367-384.

MARTINS, Gilberto de Andrade. Metodologia da investigação científica para ciências sociais aplicadas. São Paulo: Atlas, 2007.

ONU - ORGANIZAÇÃO DAS NAÇÕES UNIDAS. Atlas Brasil 2013. Programa das Nações Unidas para o Desenvolvimento, 2013. 
RUA, M. das G. Análise de políticas públicas: conceitos básicos. Brasília: BID, 1997. Programa de Apoio à Gerência Social no Brasil.

SANTAELLA, Lúcia (org.). Cidades Inteligentes: Por que, Para quem? São Paulo: Estação das Letras e Cores, 2016.

SILVA, M.O. da S. Avaliação de políticas públicas e programas sociais: aspectos conceituais e metodológicos. In: SILVA, M.O. da S. (org.). Avaliação de políticas e programas sociais: teoria e prática. São Paulo: Veras, 2001. p. 37-93.

SOUTO, Átila A.; DALL'ANTONIA, Juliano C.; HOLANDA, Giovanni Moura de (org.). As cidades digitais no mapa do Brasil: uma rota para a inclusão digital. Brasília, DF: Ministério das Comunicações, 2006. 
1 Doutor em Direito Político e Econômico pela Universidade Mackenzie; Mestre em Direito pela UFS (2014); Professor titular da graduação e do mestrado em direitos humanos do PPGD-UNIT; Líder do grupo de pesquisa "Novas tecnologias e o impacto nos Direitos Humanos", vinculado ao mestrado em direito Humanos da UNIT/SE.

E-mail: contato@diogocalasans.com

2 Acadêmica em Direito pela Universidade Tiradentes UNIT/SE; Pesquisadora do Programa de Iniciação Científica - PROVIC/UNIT; Membro do Grupo de Pesquisa "Novas Tecnologias e os Impactos nos Direitos Humanos" - UNIT/ SE. E-mail: leticiafeliciana@outlook.com.br

3 Acadêmico em Direito pela Universidade Tiradentes UNIT/SE; Pesquisador do Programa de Iniciação Científica - PROBIC/UNIT; Membro do Grupo de Pesquisa "Novas Tecnologias e os Impactos nos Direitos Humanos" - UNIT/ SE. E-mail: fagnerr73@gmail.com

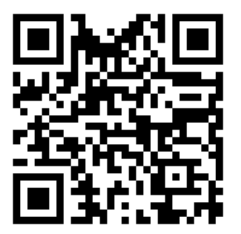

A autenticidade desse artigo pode ser conferida no site https://periodicos. set.edu.br

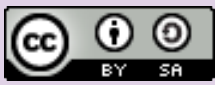

Este artigo é licenciado na modalidade acesso abertosob a Atribuição-Compartilhalgual CC BY-SA
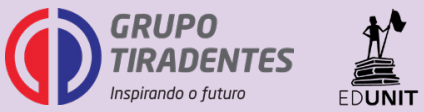